\title{
The System of High-Qualified Thung Kula Ronghai Jasmine Rice Management for Export to the People's Republic of China
}

\author{
Shiwen Lin ${ }^{1}$, Songkoon Chantachon ${ }^{1} \&$ Sastra Laoakka ${ }^{1}$ \\ ${ }^{1}$ Faculty of Cultural Science, Mahasarakham University, Muang District, Mahasarakham, Thailand \\ Correspondence: Shiwen Lin, Faculty of Cultural Science, Mahasarakham University, Muang District, \\ Mahasarakham 44000, Thailand. E-mail: kaoneaw4309@hotmail.com
}

Received: September 11, 2013

Accepted: November 21, 2013 Online Published: December 29, 2013

doi:10.5539/ass.v10n2p166

URL: http://dx.doi.org/10.5539/ass.v10n2p166

\begin{abstract}
The objectives of this qualitative research were to study the historical background of management of Thung Kula Ronghai Jasmine Rice for export to the People's Republic of China; to study current circumstances and problems of management of Thung Kula Ronghai Jasmine Rice for export to the People's Republic of China; and to study the system of high-qualified Thung Kula Ronghai Jasmine Rice management for export to the People's Republic of China. The fieldwork data and documents were collected using a survey, observations, interviews, and focus-group discussions. One hundred and five informants were selected from Surin, Roi ET, and Si Sa Ket provinces. The analysis of data was based on the objectives of the research and done descriptively using a triangulation technique. The research found that the Jasmine Rice 105 was brought to the area by government agencies for commercial purposes. Currently, the Jasmine Rice businesses in Thung Kula Ronghai were operated by private rice mills and community business organizations and the rice export was in the hands of middlemen coming from outside and making product brands and packaging themselves. The management of local mills and businesses included paddy grains purchasing, reducing of moisture, storage, processing, and packaging. Although the management as a whole did not meet the international standards, the rice export to China should do the growing of rice, processing, and exporting systematically.
\end{abstract}

Keywords: management, Thung Kula Ronghai jasmine rice, the People's Republic of China

\section{Introduction}

Historically, rice was a staple food and originally grown some 7,000 years ago. As a basis of human culture, rice-related activities comprised of planting, processing, marketing, and consuming as a staple food (Xiang, 2004, p. 62). The rice growers, known as farmers owned their land and grew rice as neatly as they could. For them, growing rice was their lives. People lived together in villages having families of their own. Family members lived and had meals together. They had peaceful lives. Rice culture thereby emphasized diligence, harmony, and unity (Pang, Lin, \& Ruan, 2006, pp. 58-59).

Rice cultivation in Thailand could be traced back to more than 5,000 years ago. Rice was a staple food, agricultural product, and export goods bringing billions of Baht each year to Thailand (Li, Ding, \& Chen, 2010, pp. 49-53). The variety of rice promoted most by Thai government was and still is Jasmine Rice 105 (Hom Mali 105). The rest included RD15, Nang Nual4, and RD6. Only RD6 is sticky rice; the rest are regular rice. The rice grown in the Northeastern Thailand has continuously been developed. Originally, the Jasmine Rice was grown in Bang Khla District, Chachoengsao Province, Thailand. This rice variety has been very popular in Thailand as well as abroad for its aroma and the low amylase starch. Unlike other kinds of rice in Thailand, Jasmine Rice 105 is still fragrant and soft after cooked (Iswilanon, 2009, p. 11). Surprisingly, the majority of the people in Northeastern still consume sticky rice, yet they grow Jasmine Rice 105 for market. In fact, the market demand for the rice was high (Singh, Singh, \& Khush, 2000, p. 86). It is accepted that the Jasmine Rice 105 was and still is the culminated rice of the world.

In Thailand, the Northeast grew the most Jasmine Rice using 19 million rais or 80 percent of total land making some 6.5 million tons of rice each year. Although the rice production per rai in the North and Central was higher than the Northeast, the aroma and softness were less than the ones of the Northeast. The Jasmine Rice grown elsewhere in Thailand was called "Provincial Jasmine Rice". The Jasmine Rice of Thung Kula Ronghai was certified for its Geographical Indication (GI) by Department of Intellectual Property, Ministry of Commerce of 
Thailand and the European Union in 2006 and 2013 respectively.

Pathumthani Rice 1 was similar to Jasmine Rice 105 in terms of its fragrance and softness. It was fortunate that Thai agricultural researchers could develop rice variety that was not sensitive to sun light. As a result, the rice could be grown in the North and Central Thailand. Such brought multiple-cropping to the irrigated areas. Farmers could make more income from selling this high quality rice, therefore, increased their land for rice planting. It was unfortunate, however, for the farmers in the Northeastern Thailand to bring Pathumthani Rice 1 and Provincial Jasmine Rice to mix with the Jasmine Rice 105 and market in Thailand and abroad.

The People's Republic of China is one of the world's rice producing, consuming, and exporting countries. Due to fast increase of population, the quality of home-grown rice, both the quality and natural characteristics, were overlooked unlike the countries that grew good quality rice, such as Thailand (Jasmine Rice), India (Basmati), U.S.A. (Lemont and Cypress) (He \& Chen, 2003, pp. 39-40).

After the reform and opening the country policy in 1980s, the People's Republic of China had a fast economic development having higher income families and the middle-class also increased drastically. The people belonging to these two economic groups had high purchasing power and needed good quality products, especially food. As a result, the internal rice market had to import good quality rice from foreign countries. It began to import 5,000 tons of Jasmine Rice in 1990. From then on, it imported the rice 200,000 tons per year, some year up to 600,000 tons. In general, the Thai Jasmine Rice was sold \$150-200 higher per ton than other kinds of rice. In China, the rice was sold twice higher than the Chinese home-grown rice. Attempts were made to mix the poor quality rice with the Thai Jasmine Rice for more profit making. Such improperly don method made the rice from Thailand unreliable (Zhang, Wang, \& Huang, 1998, pp. 10-11). The problems, so far, have not been solved successfully. Business Division of the Consulate of Thailand in the City of Guangzhou in 2009 stated that Thailand's Jasmine Rice packing in China, 90\% or more was a fake (Lu \& Liu, 2010, p. 24). As a result, the Thailand's Jasmine Rice, in the eyes of consumers in China, had lost its brand image and confidence to ensure its quality. The import volume decreased noticeably. In 2010, China imported Thailand's Jasmine Rice only 124,000 tons as compared to about 1,300 million people in China. The amount of Jasmine Rice consumed by a Chinese was less than 0.1 kilogram per year (The Correspondent of GZRB, 2011, p. 6).

As the China's economy developed rapidly some years ago, so did their lives. Their needs of good quality and high priced products followed. In order to maintain the market share of Thailand's Jasmine Rice product in China, the name of product should carry the Geographical Indication of Thung Kula Ronghai. The study of system of high-qualified Thung Kula Ronghai Jasmine Rice management was necessary for building as well as renewal trust among the consumers of Thailand's Jasmine Rice in the People's Republic of China.

\section{Research Objectives}

The research had three objectives:

1) to study the historical background of management of Thung Kula Ronghai Jasmine Rice for export to the People's Republic of China;

2) to study current circumstances and problems of management of Thung Kula Ronghai Jasmine Rice for export to the People's Republic of China; and

3) to study the system of high-qualified Thung Kula Ronghai Jasmine Rice management for export to the People's Republic of China.

\section{Research Methodology}

This qualitative cultural research chose informants purposively. They were working in private rice mills and community business organizations. The research was conducted in Surin, Roi Et, and Si Sa Ket provinces. The number of Jasmine Rice community businesses and private mills for the study included 4 from Surin, 2 from Roi Et, and 3 from Si Sa Ket provinces respectively. The research data collected using observations, interviews, and focus-group discussions. The analysis of data was based on the objectives of the research and done descriptively using a triangulation technique.

\section{Research Results}

4.1 The Historical Background of the Management of Thung Kula Ronghai Jasmine Rice for Export to the People's Republic of China

Thung Kula Ronghai was the area known for the best Jasmine Rice in Thailand, although the area was not the origin of this cultivar. Its origin was at Amphoe Bangkhla, Chachoengsao Province. The people living in Thung Kula Ronghai had sticky rice as their main staple food. They grew Jasmine Rice for market. Since then, the 
method of rice cultivation in the area has changed drastically. In the past, the people there grew rice for household consumption. Their means of production were acquired within their immediate natural environment. They planted a variety of grains with different harvest periods. More importantly, every step of rice growing and production, belief and rituals were carried out all along. They had a tradition of helping one another in rice harvest, known as Long Khag Kiaw Khao. They also took turn in threshing and carrying paddy grains from the threshing grounds to rice containers. They did not pay their neighbors but provided them with meals. Currently, however, $90 \%$ of the fields were used for planting Jasmine Rice. The farmers, directly and indirectly, were forced to rely on outside support, such as pesticides, chemical fertilizer, and machinery. Traditional beliefs and practices supported farming were not carried out as much as they used to be in the past. Young people moved to large cities looking for employment. Only old people and children were left in villages and looked after rice farming. With new methods of rice farming using seeding techniques and harvesting machines, farming was easier than how it was done in the past. It was speculated that there might be some chemical residue left in the rice product.

In the past the quality assurance of the rice for export to China was managed using only experience. Folk technologies were used: Rice paddy grains were naturally dried using sun light; dried grains were kept in silos or barns or in sacks, and milled using hand-mortars. The milled rice was put in hemp bags. Middlemen acted as rice exporters to China and other countries worldwide. They had to look for foreign markets. Sometimes, they had people, known as Yong Hangs, in Chinese, to buy and export rice on behalf of the rice exporters. Yong Hangs also negotiated with rice exporters on behalf of the mills. In the past most rice exporters lived in Bangkok and its metropolitan areas. It was difficult for the rice mills located in Thung Kula Ronghai to work closely with the middlemen who worked and lived in the areas designated above.

\subsection{The Current Circumstances and Problems of Management of Thung Kula Ronghai Jasmine Rice for Export to the People's Republic of China}

Currently, the rice businesses, including community business organizations and private rice mills, bought the paddy grains directly from the farmers. Lately, the government's rice pledging scheme had set the price of Jasmine Rice higher than the market price and the Thung Kula Ronghai farmers participated the project. Furthermore, the government and private mills bought the paddy grains from farmers without separating between the Jasmine Rice from within and outside Thung Kula Ronghai area. Such was not consistent with the Geographical Indication (GI) of the Jasmine Rice of Thung Kula Ronghai. Physically, the paddy grains were treated using local standards for designated moisture content, the mixing degree of non-Jasmine Rice, and the head rice yield. There was no inspection for aroma and chemical residue. There were two methods for reducing paddy moisture, which were sunshine and machine drying respectively. But only large-scale mills had paddy driers. There were many ways for storing paddy grains, keeping in barns, siloes, or warehouses. The larger rice mills operated in Thung Kula Ronghai area were more equipped than the smaller ones and could produce rice products with high physical qualities, well-polished, high purity degree, and no gravel mixing. The packaging was done using one-tone big bags for delivering to middlemen or exporters and various bag sizes for 10, 15, and 50 kilograms of rice for domestic markets. Hemp sacks were used for packaging of the government's project rice.

The study also found that almost all of Thung Kula Ronghai Jasmine Rice, was exported to foreign countries without the Geographical Indication, China was included. The middlemen exporters were in Bangkok and its metropolitan areas. The rice exporters did not fully understand taste and rice consumption of the customers in China. As a result, the Jasmine Rice market in China was not attractively developed. Moreover, there was no need of Yong Hangs any more due to effective communication between Thung Kula Ronghai Jasmine Rice businesses and the middlemen exporters. Due to the fact that the Thung Kula Ronghai rice businesses did not export their rice to China directly from their area, they, therefore lacked initiation applying international standards in their Jasmine Rice management, such as GMP and HACCP. They intentionally operated their rice businesses without applying Geographical Indication. If such could be done, the quality development of Thung Kula Ronghai Jasmine Rice, especially its value-added, could be achieved properly.

\subsection{The System of High-Qualified Thung Kula Ronghai Jasmine Rice Management for Export to the People's Republic of China}

The study found that individual rice growing families were far from having capacity of managing their own paddy grains, such as harvesting, drying, and storing. For the export of Jasmine Rice to the People's Republic of China alone, the local business organizations had less power in marketing and price setting as comparison with the middlemen exporters. It was suggested the government should support as well as encourage local Jasmine 
Rice businesses in order to achieve high standards, safety, and cleanliness for direct export of Jasmine Rice to China. Here are some of the activities to be taken by concerned parties.

1) to assure paddy grains' quality

The government should manage Thung Kula Ronghai Jasmine Rice paddy grains with high quality, chemical residue free, and be consistent with Geographical Indication and Good Agricultural Practice Farming System. Hence, the farmers, rice business organizations and the mills that participate the government's rice pledging project should be required to register to the Geographical Indication. Furthermore, they should differentiate the Jasmine Rice grown within and outside Thung Kula Ronghai area. They should take notes of information on the quality of rice that could be traced back. There should also be two agricultural systems matching the Geographical Indication: Good Agricultural Practice (GAP) and the Organic Systems. Since the government' designated rice price was higher than the market price, the market mechanism could attract farmers to change production methods from chemical dependency to a production system of Good Agricultural Practice.

As for organic farming system with Geographical Indication, should be developed through community businesses and farmers' group promotion. Thereby, it was enough for Geographical Indication recognized Jasmine Rice paddy grains to be checked for physical qualities as they had been done. The government's rice pledging project should base on the rice actually kept in the farmer's barns rather than delivered to the mills which government designated.

2) to assure processing quality

The processing of the high-qualified rice paddy grains should be based on high standards, cleanliness, delicacy, and safety. The large-scale rice businesses with mills and full procedures could guarantee high standards rice product and prevent contamination. Whereas small rice mills of small community businesses needed to install gravel separators and color sorters, because the rice drying method in the area made it great chances to combine gravel in paddy grains, and color sorting could separate off yellow grains, black grains, and sticky grains. In addition, for export to China, the rice product should be made of new paddy grains, and go through the international management systems of Good Manufacturing Practice (GMP), the Hazard Analysis and Critical Control Product (HACCP).

3) to package according to Chinese consumers' circumstances

The packaging of the Jasmine Rice product should take into consideration of taste and preferences of the consumers in China. The Chinese consumers were the ones who had high income and often held celebration of various occasions all year round. The Jasmine Rice product could be used as gifts. Packaging of the product should be somewhat luxurious with plastic woven bags. Since most Chinese families are small, due to the government policy, the packages of rice product either the 1st or 2 nd grade should be made 5-10 kilograms. For the brown and germinated brown rice, the packages should be 1-2 kilograms due to the low market demand. The germinated brown rice, through a steaming process, was not prone to insects, such as moths. It was necessary to use vacuum or carbon dioxide packaging method for all types of Thung Kula Ronghai Jasmine Rice products except for the germinated brown rice.

As for the information attached to the Jasmine Rice package sold in China, should be easy and short with brands and product names, Geographical Indication, product certification, product license, rice varieties, weight, processing standards, health certification, manufacturing and expiring dates, international management system certification, honor received, address, telephone number(s) and postal code, and bar-code. In addition to these, seeding and harvesting dates should be provided to consumers in China to tell them that the rice product had been made of new paddy grains which was the rice grown in season. Brochure should also be attached with the package of the rice product for public relations informing consumers that the Jasmine Rice grown in Thung Kula Ronghai is the best rice in Thailand. With all this information, the customers could be fully reassured of the product.

4) to open up new business routes and new business model for direct export

As for starting up new and convenient routes to export directly to china, such should begin at Kunming, the capital city of Yunnan Province and the city of Nanning, the capital city of Guangxi Autonomous Region of the People's Republic of China. They, being the China' big cities closest to the Northeastern Thailand where Thung Kula Ronghai is located, should be suitable for the Jasmine Rice markets using R3A, R9 and the Mekong River's navigable routes logistically. The two cities were designated by the Chinese government as the bridgehead cities facing ASEAN. The China Kunming Export and Import Commodities Fair and the China-ASEAN Expo held at Nanning City should bring opportunities for concerned parties in the area to 
communicate, coordinate, and promote Jasmine Rice export businesses. The Thung Kula Ronghai Jasmine Rice should also come forward with publicities in these occasions. The Ministry of Commerce and local governments as well as private businesses and community business organizations in Thung Kula Ronghai should attend such events and open up new market for the Jasmine Rice.

\section{Discussion}

\subsection{The Historical Background of the Management of Thung Kula Ronghai Jasmine Rice for Export to the People's Republic of China}

The origin of the Jasmine Rice was Amphoe Bangkhla, Chachoengsao Province. It was introduced to the farmers in Thung Kula Ronghai in 1959 by Rice Department, the Ministry of Agriculture and Cooperatives. Such was in agreement with Phoowadon Suwandee (2003, pp. 410-426) that farming demonstration plots carried out in Thung Kula Ronghai area covering more than 100 rais in 5 provinces: Surin, Si Sa Ket, Yasothon, Roi Et, and Maha Sarakham. The United States and Australia also participated the project. Farmers, at that time, bought the new grain variety from the government-three Baht per kilogram. The result of the project was satisfactory. Thirty years (1959-1993) later, the Jasmine Rice cultivation spread over Thung Kula Ronghai area. Nevertheless, they still grew a variety of sticky rice for household consumption. The quality of the Jasmine Rice in the area of Thung Kula Ronghai varied. Surin Province had been known for its best Jasmine Rice in the country, its market price was higher than other areas in Thailand.

\subsection{The Current Circumstances and Problems of Management of Thung Kula Ronghai Jasmine Rice for Export to the People's Republic of China}

Several activities were carried out in order to examine the quality of the Jasmine Rice. It included the measurement of moisture content, the separation of impurities in the paddy grains, the monitoring of head rice from milled rice. Such was in agreement with Ornanong Naiwikul (2007, pp. 86-88) that there were three steps to be taken for purchasing the paddy from the farmers: random checking while the paddy was loaded in trucks 6-12 different spots for each truck, checking the moisture content and contamination in the laboratory; and pricing was done after checking the quality of rice by grinding. If such inspection was acceptable, the price was designated and recognized by both buyers and sellers. For milling the rice, four steps were taken: cleaning the paddy grains; cracking, polishing of rice bran, and polishing white rice; classifying rice by sizes before packaging; and packaging.

The study found that harvesting time, drying and storage of paddy grains were related to management of Thung Kula Ronghai Jasmine Rice. Such was in agreement with Kruawan Atthawiriyasuk (1993, pp. 1-53) that if the harvest was done too early or too late, the quality and quality of the milled rice was affected. If the paddy grains were to be stored for 2-3 months, the moisture content of the grains should not exceed 14 percent. If a longer duration was needed the moisture content should be 12-12.5 percent. The paddy grains should be kept in clean and airy barns and there are nets to prevent birds, rats, and other animals. If the grains were kept or stored in bags, the bags should be kept 5-6 inches above the concrete floor preventing moisture absorption from the ground. Meanwhile, there should be air space between rows to help keep the grains in good condition and color.

\subsection{The System of High-Qualified Thung Kula Ronghai Jasmine Rice Management for Export to the People's Republic of China}

The Jasmine Rice of Thung Kula Ronghai received Geographical Indication from Thailand and the European Union. The industry of Thung Kula Ronghai Jasmine Rice should also follow the Geographical Indication (GI). The community rice businesses, to some extent, intended to operate Thung Kula Ronghai Jasmine Rice upon Geographical Indication. They seemed to lack market and opportunities to change the way they operated their businesses, for could not export their products directly and the middlemen were not willing to pay higher price for the Geographical Indication. The government, on the other hand, should develop the Jasmine Rice industry by asking the farmers and mills that participate the rice pledging scheme to accept the Geographical Indication. Such was consistent with structural-functional theory (Chantachon, 2010, pp. 17-19) that society was just like organism. To understand it profoundly, we need to study the structure of each society. Social structures coordinate with one another. If one part of society fails to function, the whole society will also fail. It will affect other structure like a chain effect. The society will finally collapse. The government should not overlook the problem. Such was consistent with theory of cultural ecology due to the change brought by the government's rice pledging policy scheme upon the Geographical Indication. The ecology of rice production and rice businesses in Thung Kula Ronghai could force farmers and rice businesses to change the way they grew rice or operated businesses. All was for survival. However, the development of Thung Kula Ronghai Jasmine Rice upon the Geographical Indication was consistent with market failure theory in micro-economics. If purchasers and 
producers have equal reliable and related information, such as prices and quality of products, decision making could then further made. In the event that either party has less information than the other or having asymmetric information, the buyers do not know the fine quality of the products they are buying (Tantivasadakarn, 2007, pp. 315-369).

In addition, the system of high-qualified Thung Kula Ronghai Jasmine Rice management for export to the People's Republic of China was in consistence with cultural diffusion theory (Chantachon, 2010, pp. 59-60) that cultural Innovation, to be acceptable, should be of 5 characteristics, such as, (1) more useful than the old one (Relative Advantage); (2) consistent with the culture of the receiving society (compatibility); (3) not very complicating (Less Complexity); (4) can be divided into little units to be tried (Divisibility); (5) can be seen and easily understood (Visibility).

\section{References}

Atthawiriyasuk, K. (1993). The Physical Quality of Paddy Grains and Its Processing. Rice Research Institute's Postharvest Training Course Materials at Phatthalung Rice Research Center. Bangkok: Department of Agriculture, Ministry of Agriculture and Cooperatives.

Chantachon, S. (2010). The Theories of Culture and Society. MahaSarakham: MahaSarakham University Publishing House.

Dong, N. X. (2004). Talking about Rice Culture. Reclaiming and Rice Cultivation.

He, Z. W., \& Chen, Y. F. (2003, December). Analysis of the Competitiveness of Rice Produced in China and the Strategies. Science \& Technology Progress and Policy.

Isvilanont, S. (2009, October). Who will Maintain the Precious Identity of Thai Jasmine Rice. Bangkok Business Newspaper.

Li, Z., Ding, S. J., \& Chen, F. B. (2010, September). An Analysis of Rice Production and Trade in Countries Mainly Producing and Trading Rice. Journal of International Trade, 31(5).

Lu, H. M., \& Liu, Z. L. (2010). Thai Jasmine Rice Packaged in China 90\% is fake product. Beijing Agriculture. Mid-August Issue.

Naiwikul, O. (2007). Rice: Science and Technology. Bangkok: Kasetsart University.

Pang, Q. L., Lin, H., \& Ruan, L. Q. (2006). Probing Rice Route and Developing Rice Culture. Farm Products Processing.

Singh, P. K., Singh, U. S., \& Khush, G. S. (2000). Aromatic Rice. New York: Science Publisher.

Suwandee, P. (2003). Jasmine Rice in the Culture of Thung Kula Ronghai Salty, Dry, Droughty, and Sandy. Thung Kula Ronghai History of 2500 Years: The Transformation from the Backwardness in the Past to the Nowadays' Richness of Jasmine Rice. Bangkok: Matichon Publishing House.

Tantivasadakarn, C. (2007). Microeconomics: Theories and Appliance. Bangkok: Thammasat University Publishing House.

The Correspondent of GZRB. (2011, June). Opening the General Assembly on Thailand Rice and World Rice Standard Convention. Guangzhou Daily.

Zhang, Z. M., Wang, B. J., \& Huang, X. (1998). Jasmine Rice Market Survey and the Purity of the Jasmine Rice Imported from Thailand. Jiangxi Agricultural Science \& Technology, 3.

\section{Copyrights}

Copyright for this article is retained by the author(s), with first publication rights granted to the journal.

This is an open-access article distributed under the terms and conditions of the Creative Commons Attribution license (http://creativecommons.org/licenses/by/3.0/). 